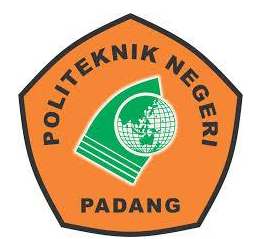

Jurnal IImiah Rekayasa Sipil

Available online at : http://ejournal2.pnp.ac.id/index.php/iirs/ Terakreditasi SINTA Peringkat 5

\title{
Analisa Investasi Pemilihan Hydraulic Excavator dengan Pertimbangan Aspek Teknis dan Ekonomis
}

\author{
${ }^{1)}$ Yan Partawijaya, ${ }^{2}$ Desmon Hamid, ${ }^{3)}$ Mukhlis, ${ }^{4)}$ Jajang Atmaja, ${ }^{5}$ Muhammad Faris \\ 1), 2), 3), 4), 5)Teknik Sipil Politeknik Negeri Padang \\ Email : Yan_parta21@yahool.com,desmon_hamid@yahoo.co.uk, palito_alam@yahoo.com, \\ Atmaja_jajang@yahoo.com,fadhlullah.faris94@gmail.com
}

\begin{abstract}
ABSTRAK
The ownership of heavy equipment is one of the most interesting business at this time, because the indonesian government is actively developing infrastructure, mining, plantation and agriculture sectore. So, it will be very profitable to do this heavy equipment business if it followed an accurate investment analysis. In this research, researchers took a case study on analyzing the selection of hydraulic excavator from 5 different brands, its Komatsu, Hitachi, Caterpillar, Kobelco and Hyundai with 3 different classes (economical, medium and high mode). This research was conducted by collecting primary data (interviews and field surveys) and secondary data (previeos research journal and literature studies) as supporting data. Data processing with reference to Permen PU no.11/PRT/M/2013. Decision making analysis is based on calculation of Nett Present Value (NPV) method, Internal Rate of Return (IRR) method and Break Event Point (BEP) method.

After conducting the research, researcher concludes as follows : in the economical class, researcher recommends CAT 313D2 to be invested for the purpose of being rented or used alone. In the medium class, researcher recommends Kobelco SK 200-10 to be invested for the purpose of being rented. In the high mode class, researcher recommends Kobelco SK 330 to be invested for the pupose of being rented. The recommendation that the researcher describes are not absolute decisions to be followed and only as a consideration for investors.
\end{abstract}

Keywords : Investment, excavator, recommendation

(C) 2019 JurnalllmiahRekayasaSipil

\section{PENDAHULUAN}

Memiliki alat berat sendiri adalah sebuah investasi jangka panjang yang dapat memberikan keuntungan apabila kajian dilakukan dengan cermat. Dengan memiliki alat berat, perusahaan atau investor selain bisa menggunakan untuk kebutuhan sendiri, alat tersebut juga dapat disewakan..

Beberapa kasus dalam investasi alat ini, dimana pemilik alat berat lebih tertarik pada harga alat yang murah, diskon yang cukup besar ataupun subsidi bunga dari pihak penjual tanpa mempertimbangkankemampuan

operasional alat dilapangan, seperti tenaga alat yang tidak mendukung, pemakaian bahan bakar yang tidak efisien ataupun biaya penggantian spare part yang mahal. Tentunya hal ini akan berimbas pada berkurangnya ketertarikan pihak lain untuk menyewa alat tersebut.

Pembahasan disini hanya alat berat mekanik jenis excavator dari berbagai 


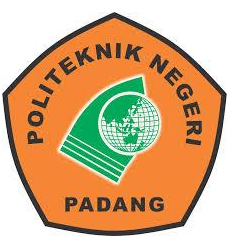

\section{Jurnal IImiah Rekayasa Sipil \\ Available online at : http://ejournal2.pnp.ac.id/index.php/iirs/ Terakreditasi SINTA Peringkat 5}

brand yang tersedia di Provinsi Sumatera kapasitas bucket seperti CAT, Komatsu, Kobelco, Hitachi dan Hyundai.

\section{Tujuan penelitian}

Adapun tujuan dari penelitian ini adalah

Melakukan kajian analisis investasi ekonomis dan analisa teknis masing-masing alat dan memberikan rekomendasi terhadap alat berat yang terbaik dari indikator-indikator tersebut.

\section{Manfaat penelitian}

dapat menghasilkan sistem perhitungan numerik dalam investasi excavator yang akan mempermudah investor ketika melakukan pertimbangan investasi dan mempermudah pemilihan alat dari hasil komparasi dengan banyak brand yang ditampilkan dalam bentuk tabulasi dan grafis.

\section{TINJAUAN PUSTAKA}

\section{Pengertian Investasi}

investasi adalah suatu aktifitas dengan usaha penarikan sumber-sumber dana yang dipakai untuk mengadakan barang modal pada saat sekarang dan dengan barang modal tersebut akan dihasilkan aliran produk baru dimasa yang akan datang (Fitzgeral,2015).

\section{Studi Kelayakan Investasi}

Studi kelayakaan investasi adalah suatu tindakan yang dilakukan untuk mengetahui prospek dari suatu proyek investasi yang mendasari suatu keputusan diterima atau ditolaknya investasi tersebut, Kamaruddin Ahmad (2011).
Barat dengan spesifikasi alat yang setara.

\section{Hydraulic Excavator}

Hydraulic Excavator sendiri adalah alat serba guna yang dapat untuk menggali tanah, membuat parit, memuat material ke dump truck atau kayu ke trailer. Dengan kombinasi penggatian attachment, maka dapat digunakan untuk memecah batu, mencabut tanggul, membongkar aspal dan lain-lain.

\section{Biaya Alat Berat}

Biaya alat berat dibagi dua yaitu biaya kepemilikan alat dan biaya pengoprasian alat. Kontraktor yang memiliki alat berat harus menanggung biaya yang disebut biaya kepemilikan alat berat (ownership cost). Pada saat alat berat dioperasikan maka akan ada biaya pengoprasian (operation cost).

1. Depresiasi adalah penurunan nilai alat yang dikarenakan adanya kerusakan, pengurangan dan harga pasaran alat. Penurunan nilai alat ini berkaitan degan semakin meningkatnya umur alat. Nilai deprsiasi ini dihitung dengan menggunakan metode Garis Lurus (Straight Line Method) yaitu : $D_{k}=\underline{P-S}$

$\mathrm{n}$

1. Biaya Kepemilikan alat dengan asumsi tanpa memperhitungkan bunga, maka rumus yang digunakan adalah:

$$
R=\frac{S(n+1)}{2 n^{2}}
$$

Biaya Operasional, yaitu biaya yang terjadi selamat unit beroperasi, terdiri dari :

a. Biaya bahan bakar

Rumus penggunaan bahan bakar per-jam adalah $=\mathrm{k} \times$ HP $\times$ eff $\times$ Harga Solar/liter 


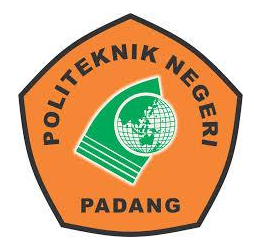

\section{Jurnal IImiah Rekayasa Sipil \\ Available online at : http://ejournal2.pnp.ac.id/index.php/iirs/ Terakreditasi SINTA Peringkat 5}

Dimana : $k=$ koefisien konsumsi bahan bakar

b. Biaya pelumas

harga oli/ltr $x$ kapasitas tanki $x \frac{\text { jam kerja/tahun }}{\text { interval (jam) }}$

c. Biaya workshop

$$
(6,25 \% \text { s.d } 8,75 \%) x \frac{\text { harga unit }}{\text { umur ekonomis }}
$$

d. Biaya perbaikan

$$
(12,5 \%-17,5) x \frac{\text { Harga unit }}{\text { umur ekonomis }}
$$

e. Biaya operator

$$
\begin{aligned}
& \text { Operator }=(1 \text { orang/jam }) \times \text { Upah/jam } \\
& \text { Pembantu }=(1 \text { orang/jam }) \times \text { Upah/jam }
\end{aligned}
$$

\section{Penilaian Investasi}

Tujuan perhitungan investasi untuk mengetahui sejauh mana gagasan usaha yang direncanakan dapat memberikan manfaat baik manfaat keuangan maupun manfaat sosial. Penilaian Investasi dapat dibedakan yaitu:

1. Metode Net Present Value (NPV)

Net Present Value (NPV) ialah metode yang menghitung nilai bersih atau netto pada waktu sekarang atau present. Yang dimaksud dari present ialah tetntang penjelasan waktu awal perhitungan yang bertepatan dengan waktu evaluasi dilakukan atau disebut pada periode tahun ke-0 dalam perhitungan cash flow investasi. Suatu cash flow investasi tidak selalu dapat diperoleh secara lengkap, yang terdiri dari cash-in dan cash-out, dapat juga diukur langsung aspek biayanya saja. Cash flow yang hanya benefit, perhitungannya disebut present worth of benefit (PWB), sedangkan jika yang diperhitungkan hanya cash-out ialah present worth of cost (PWC) sementara NPV diperoleh dari : NPV = PWB - PWC.

Dimana :

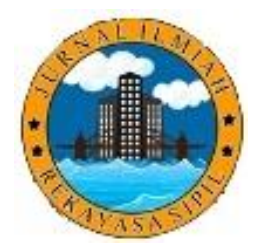

NPV > 0 maka investasi tersebut menguntungkan (Feasible)

NPV < 0 maka investasi tersebut tidak menguntungkan (Unfeasible)

2. Metode Internal Rate of Return (IRR)

Metode IRR adalah mencari suku bunganya disaat NPV sama dengan nol. Jadi metode IRR ini yang dihasilkan berkaitan dengan tingkat kemampuan cash flow dalam mengembalikan investasi yang dijelaskan dalam bentuk \% periode waktu. Menjelaskan juga seberapa kemampuan cash flow dalam mengembalikan modalnya dan seberapa besar pula kewajiban yang harus dipenuhi. Kemampuan ini yang disebut dengan Internal Rate of Return (IRR), sedangkan kewajiban disebut dengan Minimum Atractive Rate of Return (MARR). Dengan demikian, suatu rencana investasi akan dikatakan layak atau menguntungkan jika:

$$
\text { IRR > MARR. }
$$

3. Metode Break Even Point (BEP) adalah titik pulang pokok dimana total revenue $=$ total $\operatorname{cost}(\mathrm{TR}=\mathrm{TC})$.

\section{Produktifitas Excavator}

Produktifitas adalah hasil produksi dalam satuan waktu seperti m3/jam atau ton/jam. Sementara menurut Permen PU no 11PRT-M-2013, produktifitas dapat diartikan sebagai perbandingan antara output (hasil 


\section{Jurnal IImiah Rekayasa Sipil}

Available online at : http://ejournal2.pnp.ac.id/index.php/iirs/ Terakreditasi SINTA Peringkat 5

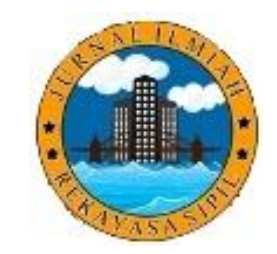

produksi) terhadap input (komponen produksi seperti kondisi alat dan waktu). Untuk menghitung produktifitas excavator dengan menggunakan rumus berdasarkan pada permen PU no.11-PRT-M-2013, sebagaimana berikut :

Kapasitas poduksi/jam $=\frac{V x F b x F a x 60}{T s 1 x F v}$

Dimana $: \mathrm{V}=$ Kapasitas bucket $(\mathrm{m} 3)$

$\mathrm{Fb}=$ faktor bucket

$\mathrm{Fa}=$ faktor efisiensi alat

$\mathrm{Fv}=$ faktor konversi

Ts1 = Waktu siklus

Waktu siklus dapat dihitung dengan berasumsi seperti pada rumus berikut :
Ts1 $=\mathrm{t} 1+\mathrm{t} 2+\mathrm{t} 3+\mathrm{t} 4$
T1 = waktu swing (bucket tanpa muatan)
T2 = waktu gali
T3 = waktu swing (bucket dengan muatan)
T4 = waktu buang
$60=$ perkalian 1 jam ke menit

\section{METODE PENELITIAN}

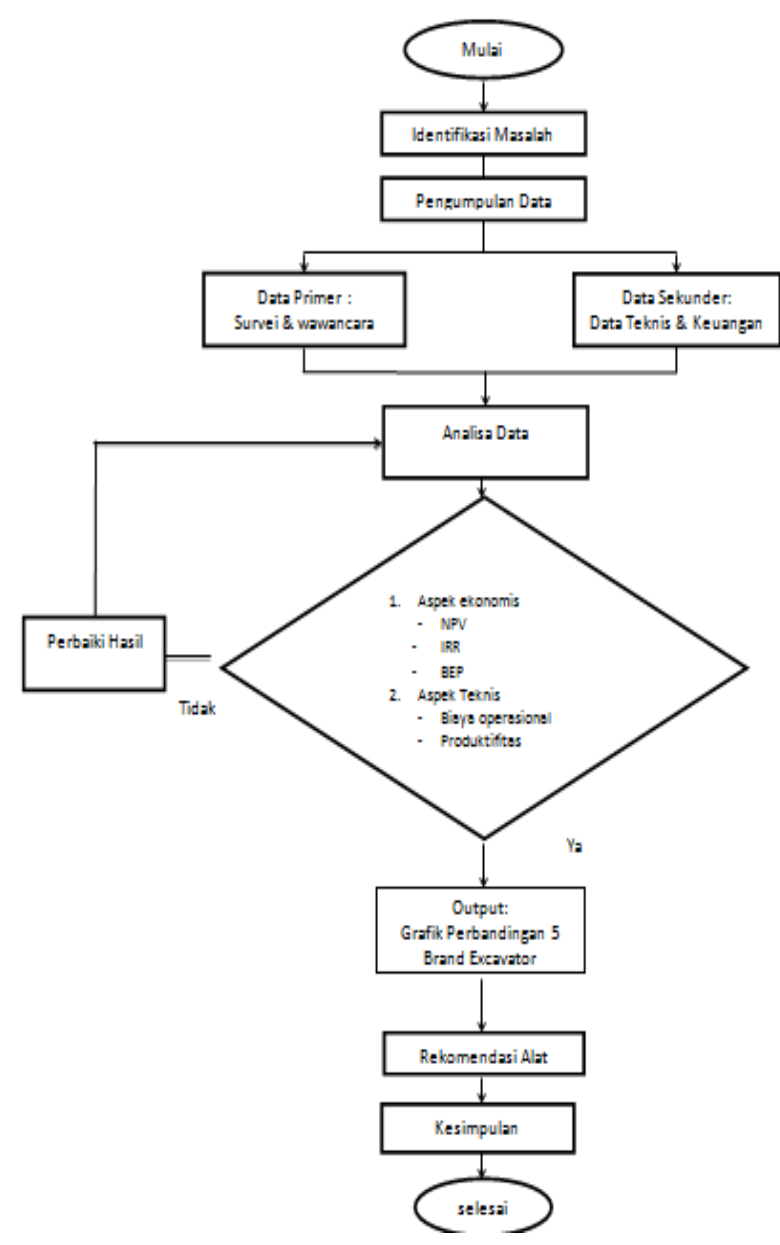




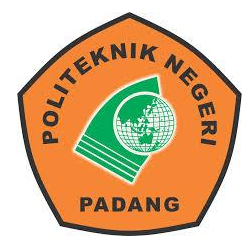

Available online at : http://ejournal2.pnp.ac.id/index.php/iirs/ Terakreditasi SINTA Peringkat 5

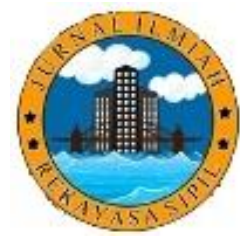

\section{HASIL DAN PEMBAHASAN}

\subsection{Klasifikasi Hydraulic Excavator}

\begin{tabular}{|c|c|c|c|c|}
\hline \multirow{2}{*}{ no } & \multirow{2}{*}{ Perbedaan } & \multicolumn{3}{|c|}{ Kelas } \\
\cline { 3 - 5 } & Nilai Investasi & $\begin{array}{c}\text { Ek 800 juta - Rp 1,1 } \\
\mathrm{M}\end{array}$ & $\begin{array}{c}\text { Rp 1,2 M-Rp 1,6 } \\
\text { M }\end{array}$ & $\begin{array}{c}\text { Rp 2,5 M-Rp 3,5 } \\
\text { M }\end{array}$ \\
\hline 2 & Bobot Unit & 10 ton & 20 ton & 30 ton \\
\hline 3 & Kapasitas Bucket & $0,5 \mathrm{~m} 3$ & $0,9-1,2 \mathrm{~m} 3$ & $1,5-2 \mathrm{~m} 3$ \\
\hline 4 & Horse Power & $85-100 \mathrm{Hp}$ & $150-180 \mathrm{Hp}$ & $200-250 \mathrm{Hp}$ \\
\hline & & $\begin{array}{c}\text { Pada umumnya } \\
\text { digunakan pada } \\
\text { pekerjaan pertanian } \\
\text { atau perkebunan dan } \\
\text { pekerjaan konstruksi } \\
\text { ringan seperti } \\
\text { penggalian parit }\end{array}$ & $\begin{array}{c}\text { Pada umunya } \\
\text { digunakan untuk } \\
\text { pekerjann } \\
\text { konstruksi dengan } \\
\text { volume besar dan } \\
\text { penggalian yang } \\
\text { relatif berat }\end{array}$ & $\begin{array}{c}\text { Pada umumnya } \\
\text { digunakan untuk } \\
\text { pekerjaan } \\
\text { konstruksi berat, } \\
\text { volume besar serta } \\
\text { sangat cocok untuk } \\
\text { pekerjaan } \\
\text { pertambangan }\end{array}$ \\
\hline
\end{tabular}

\subsection{Spesifikasi Hydraulic Excavator}

Sebelum melakukan komparasi data teknis alat, hal petama yang harus dilakukan adalah mengetahui perbandingan apple to apple dari spec yang dimiliki oleh masing-masing brand.

\subsection{Nilai Investasi}

\begin{tabular}{c|cc|cc|c|}
\hline \multirow{2}{*}{ Brand } & \multicolumn{3}{|c|}{ Kelas } \\
\cline { 2 - 6 } & \multicolumn{2}{|c|}{ Ekonomis } & \multicolumn{2}{|c|}{ Medium } & high mode \\
\hline Komatsu & $\operatorname{Rp}$ & $1.320 .000 .000,00$ & $\operatorname{Rp} 1.650 .000 .000,00$ & $\operatorname{Rp~} 3.520 .000 .000,00$ \\
\hline Hitachi & $\operatorname{Rp} 1.072 .500 .000,00$ & $\operatorname{Rp} 1.430 .000 .000,00$ & $\operatorname{Rp} 2.530 .000 .000,00$ \\
\hline CAT & $\operatorname{Rp}$ & $1.265 .000 .000,00$ & $\operatorname{Rp}$ & $1.622 .500 .000,00$ & $\operatorname{Rp} 3.630 .000 .000,00$ \\
\hline Kobelco & $\operatorname{Rp} 1.110 .000 .000,00$ & $\operatorname{Rp} 1.390 .000 .000,00$ & $\operatorname{Rp~} 2.430 .000 .000,00$ \\
\hline Hyundai & $\operatorname{Rp} 1.155 .000 .000,00$ & $\operatorname{Rp} 1.430 .000 .000,00$ & $\operatorname{Rp~} 2.530 .000 .000,00$ \\
\hline
\end{tabular}

\subsection{Pembahasan}

\section{a. Excavator Kelas Ekonomis}

\section{Aspek Ekonomis}

Menghitung biaya pendapatan dan pengelua-

ran excavator kelas ekonomis.

\begin{tabular}{|c|c|c|c|c|}
\hline \multirow{2}{*}{ Brand } & \multicolumn{5}{|c|}{ Aspek Ekonomis } \\
\cline { 2 - 5 } & \multirow{2}{*}{ Pendapatan(Rp/thn) } & \multicolumn{3}{|c|}{ Pengeluaran(Rp/thn) } \\
\cline { 3 - 5 } & & Tahun 1-2 & Tahun 3-4 & Tahun 5 \\
\hline Komatsu & Rp. 380.000.000,- & $\operatorname{Rp} 80.520 .000,00$ & $\operatorname{Rp} 87.120 .000,00$ & $\operatorname{Rp} 93.720 .000,00$ \\
\hline Hitachi & Rp. 340.000.000,-- & $\operatorname{Rp} 65.422 .500,00$ & $\operatorname{Rp} 70.785 .000,00$ & $\operatorname{Rp} 76.147 .500,00$ \\
\hline CAT & Rp. 400.000.000,-- & $\operatorname{Rp} 77.165 .000,00$ & $\operatorname{Rp} 83.490 .000,00$ & $\operatorname{Rp} 89.815 .000,00$ \\
\hline Kobelco & Rp. $340.000 .000,-$ & $\operatorname{Rp} 67.710 .000,00$ & $\operatorname{Rp} 73.260 .000,00$ & $\operatorname{Rp} 78.810 .000,00$ \\
\hline Hyundai & Rp. $340.000 .000,-$ & $\operatorname{Rp} 70.455 .000,00$ & $\operatorname{Rp} 76.230 .000,00$ & $\operatorname{Rp} 82.005 .000,00$ \\
\hline
\end{tabular}

Kemudian melakukan pengujian kelayakan investasi excavator kelas ekonomis dengan hasil sebagai berikut :

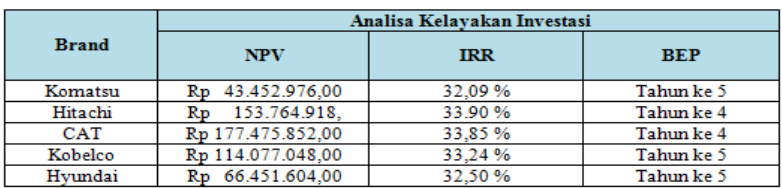

\section{Aspek Teknis}

Menghitung biaya operasional alat yang terdiri dari biaya bahan bakar, pelumas, workshop, perbaikan dan upah operator, sehingga diperoleh sebagai berikut :

\begin{tabular}{|c|c|}
\hline Brand & Biaya Operasional Excavator \\
\hline komatsu & $\operatorname{Rp~} 332.586 .371,00 /$ thn \\
\hline hitachi & $\operatorname{Rp~} 319.225 .410,00 /$ thn \\
\hline CAT & $\operatorname{Rp~} 346.901 .067,44 /$ thn \\
\hline Kob elco & $\operatorname{Rp~345.161.978,00/thn~}$ \\
\hline hyundai & $\operatorname{Rp~310.788.500,00/thn~}$ \\
\hline
\end{tabular}

Kemudian menghitung produktifitas excavator kelas ekonomis, sebagai berikut :

\begin{tabular}{|l|l|c|c|}
\hline \multicolumn{1}{|c|}{ Brand } & \multicolumn{1}{c|}{ tipe } & produktifitas & satuan \\
\hline komatsu & PC 130F-8 & 98,604 & $\mathrm{~m} 3 / \mathrm{jam}$ \\
\hline hitachi & ZX 130H-5G & 117,39 & $\mathrm{~m} 3 / \mathrm{jam}$ \\
\hline CAT & $313 \mathrm{D} 2$ & 131,97 & $\mathrm{~m} 3 / \mathrm{jam}$ \\
\hline kobelco & SK 130HDL & 91,30 & $\mathrm{~m} / \mathrm{jam}$ \\
\hline hyundai & R 110-7 & 102,71 & $\mathrm{~m} 3 / \mathrm{jam}$ \\
\hline
\end{tabular}

\section{Analisa Pengambilan Keputusan}

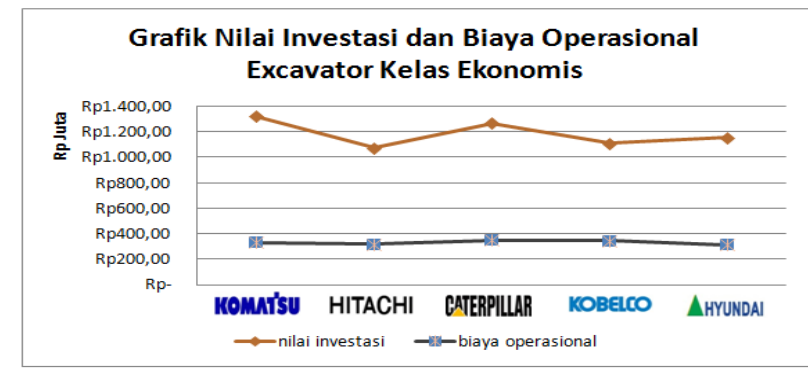

Bisa dilihat bahwa, nilai investasi excavator kelas ekonomis memiliki perbedaan yang cukup signifikan antara nilai tertinggi dan terendah, dengan selisih nilai Rp. 210.000.000,-. Namun pada biaya operasional, tidak terdapat perbedaan yang signifikan dengan biaya yang hampir sama atau merata meskipun memiliki nilai investasi yang tinggi.

Pada aspek teknis, CAT 313D2memiliki nilai investasi kedua tertinggi setelah komatsu PC 


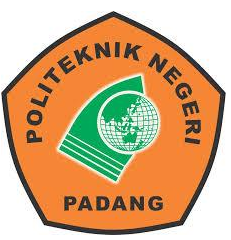

Available online at : http://ejournal2.pnp.ac.id/index.php/iirs/ Terakreditasi SINTA Peringkat 5

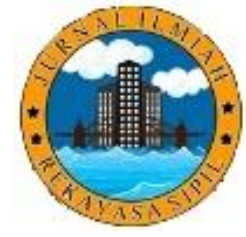

130F-8, yaitu sebesar Rp. 1.265.000.000,- dan membutuhkan biaya operasional Rp. 346.901.067,-/tahun. Walaupun CAT 313D2 membutuhkan biaya operasional $4,6 \%$ lebih tinggi daripada biaya operasional rata-rata, tetapi mampu menghasilkan produktifitas $17,8 \%$ lebih besar daripada produktifitas rata-rata. Sehingga dari aspek teknis CAT 313D2 penulis rekomendasikan untuk dinvestasikan maupun digunakan untuk sendiri.

\section{b. Excavator Kelas Medium}

\section{Aspek Ekonomis}

Menghitung biaya pendapatan dan pengeluaran excavator kelas medium.

\begin{tabular}{|c|c|c|c|c|}
\hline \multirow{3}{*}{ Brand } & \multicolumn{4}{|c|}{ Aspek Ekonomis } \\
\hline & \multirow{2}{*}{ Pendapatan(Rp/thn) } & \multicolumn{3}{|c|}{ Pengeluaran(Rp/thn) } \\
\hline & & Tahun 1-2 & Tahun 3-4 & Tahun 5 \\
\hline Komatsu & Rp. $550.000 .000,-$ & Rp 33.000.000,00 & Rp $108.900 .000,00$ & Rp $117.150 .000,00$ \\
\hline Hitachi & Rp. $500.000 .000^{-}-$ & Rp $100.650 .500,00$ & $\operatorname{Rp} 94.830 .000,00$ & Rp $101.530 .000,00$ \\
\hline CAT & Rp. $550.000 .000_{2-}^{-}$ & Rp 87.230.000,00 & Rp 107.085.000,00 & Rp 115.197.500,00 \\
\hline Kobelco & Rp. $500.000 .000_{0}^{-}$ & $\operatorname{Rp} 98.972 .500,00$ & $\operatorname{Rp} 91.740 .000,00$ & Rp 98.690.000,00 \\
\hline Hyundai & Rp. $500.000 .000_{2-}^{-}$ & $\operatorname{Rp} 87.230 .000,00$ & $\operatorname{Rp} 94.830 .000,00$ & Rp 101.530.000,00 \\
\hline
\end{tabular}

Kemudian melakukan pengujian kelayakan investasi excavator kelas medium dengan hasil sebagai berikut :

\begin{tabular}{|c|c|c|c|}
\hline \multirow{2}{*}{ Brand } & \multicolumn{3}{|c|}{ Analisa Kelayakan Investasi } \\
\cline { 2 - 4 } & NPV & IRR & BEP \\
\hline Komatsu & $\operatorname{Rp~} 338.618 .720,00$ & $34,92 \%$ & Tahun ke 4 \\
\hline Hitachi & $\operatorname{Rp} 381.919 .224,00$ & $35.93 \%$ & Tahun ke 4 \\
\hline CAT & $\operatorname{Rp} 367.723 .158,00$ & $35,27 \%$ & Tahun ke 4 \\
\hline Kobelco & $\operatorname{Rp} 424.252 .952,00$ & $36,55 \%$ & Tahun ke 4 \\
\hline Hyundai & $\operatorname{Rp} 381.919 .224,00$ & $35,93 \%$ & Tahun ke 4 \\
\hline
\end{tabular}

\section{Aspek Teknis}

Menghitung biaya operasional alat yang terdiri dari biaya bahan bakar, pelumas, workshop, perbaikan dan upah operator, sehingga diperoleh sebagai berikut

\begin{tabular}{|c|c|}
\hline brand & Biaya Operasional Excavator Kelas Medium \\
\hline komatsu & $\operatorname{Rp~} 498.552 .676,00 /$ thn \\
\hline hitachi & $\operatorname{Rp} 532.592 .200,00 /$ thn \\
\hline CAT & $\operatorname{Rp~} 498.868 .952,00 /$ thn \\
\hline Kobelco & $\operatorname{Rp} 510.597 .228,00 /$ thn \\
\hline hyundai & $\operatorname{Rp~} 479.902 .000,00 /$ thn \\
\hline
\end{tabular}

Kemudian menghitung produktifitas excavator kelas medium, sebagai berikut :

\begin{tabular}{|l|l|c|c|}
\hline \multicolumn{1}{|c|}{ Brand } & \multicolumn{1}{c|}{ Tipe } & Produktifitas & Satuan \\
\hline komatsu & PC 200-8Mo & 166,73 & $\mathrm{~m} / \mathrm{jam}$ \\
\hline hitachi & ZX 210H-5G & 172,38 & $\mathrm{~m} 3 / \mathrm{jam}$ \\
\hline CAT & $320 \mathrm{D} 2$ & 154,38 & $\mathrm{~m} 3 / \mathrm{jam}$ \\
\hline kobelco & SK 200-10 & 160,32 & $\mathrm{~m} / \mathrm{jam}$ \\
\hline hyundai & R 220-LC9A & 148,87 & $\mathrm{~m} 3 / \mathrm{jam}$ \\
\hline
\end{tabular}

\section{Analisa Pengambilan Keputusan}

Berdasarkan ketiga indikator aspek ekonomis pada kelas medium, maka excavator, yaitu Kobelco SK 200-10 penulis rekomendasikan untuk dipilih dalam aktifitas investasi, karena secara ekonomis Kobelco SK 200-10 memiliki nilai NPV tertinggi, persentase pengembalian modal atau IRR terbesar dengan waktu pengembalian tercepat.

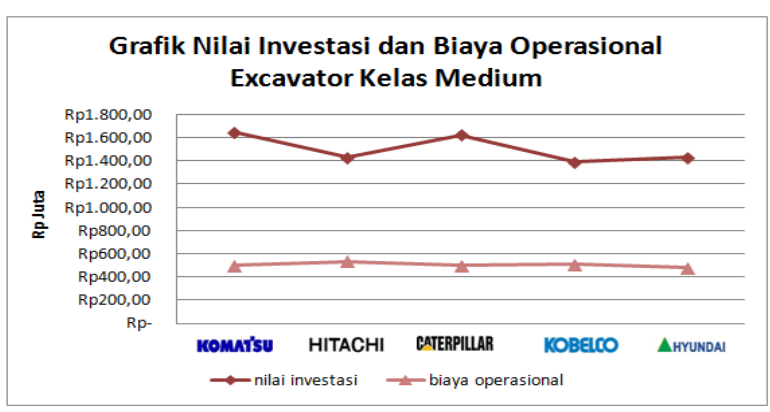

Bisa dilihat bahwa, nilai investasi excavator kelas medium memiliki perbedaan yang cukup signifikan antara nilai tertinggi dan terendah, dengan selisih nilai Rp. 260.000.000,-. Pada biaya operasional, tidak terdapat perbedaan yang signifikan dengan biaya yang rata-rata hampir sama dengan Hyundai adalah alat dengan biaya operasional terendah, tetapi meskipun Komatsu dan Caterpillar memiliki nilai investasi tertinggi, justru memutuhkan biaya operasional yang lebih rendah daripada Hitachi dan Kobelco yang memiliki nilai investasi terendah.

Secara ekonomis Kobelco SK 200-10 layak untuk diinvestasikan, namun pada aspek 


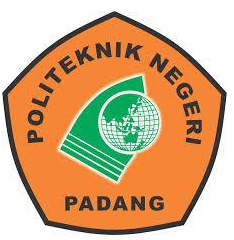

Available online at : http://ejournal2.pnp.ac.id/index.php/iirs/ Terakreditasi SINTA Peringkat 5

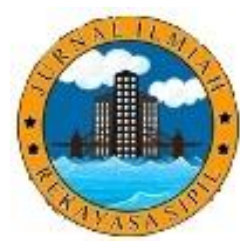

teknis, Kobelco SK 200-10 membutuhkan biaya operasional Rp. 510.597.228,-/tahun, kedua tertinggi setelah Hitachi ZX 210H-5G dan menghasilkan produktifitas ketiga terendah yaitu 160,32 m3/jam. Maka secara teknis, Kobelco SK 200-10 tidak direkomendasikan untuk digunakan sendiri, tetapi lebih cocok pada aktifitas investasi yang ditujukan untuk disewakan.

\section{c. Excavator Kelas High Mode}

\section{Aspek Ekonomis}

Menghitung biaya pendapatan dan pengeluaran excavator kelas ekonomis.

\begin{tabular}{|c|c|c|c|c|}
\hline \multirow{3}{*}{ Brand } & \multicolumn{4}{|c|}{ Aspek Ekonomis } \\
\hline & \multirow{2}{*}{ Pendapatan(Rp/thn) } & \multicolumn{3}{|c|}{ Pengeluaran(Rp/thn) } \\
\hline & & Tahun 1-2 & Tahun 3-4 & Tahun 5 \\
\hline Komatsu & Rp. $1.000 .000 .000_{3^{-}}$ & $\operatorname{Rp} 214.720 .000,00$ & $\operatorname{Rp} 232.320 .000,00$ & $\operatorname{Rp} 249.980 .000,00$ \\
\hline Hitachi & Rp. $800.000 .0000^{-}$ & Rp $154.330 .000,00$ & $\operatorname{Rp} 166.980 .000,00$ & $\operatorname{Rp} 179.630 .000,00$ \\
\hline CAT & Rp. 1.060 .000 .000 & $\operatorname{Rp} 3.630 .230 .000,00$ & $\operatorname{Rp} 239.580 .000,00$ & $\operatorname{Rp} 257.730 .000,00$ \\
\hline Kobelco & Rp. $800.000 .000,-$ & Rp 148.230.000,00 & $\operatorname{Rp} 160.380 .000,00$ & $\operatorname{Rp} 172.530 .000,00$ \\
\hline Hyundai & Rp. 760.000 .000 & Rp $154.330 .000,00$ & Rp 154.330.000,00 & $\operatorname{Rp} 179.630 .000,00$ \\
\hline
\end{tabular}

Kemudian melakukan pengujian kelayakan investasi excavator kelas high mode dengan hasil sebagai berikut :

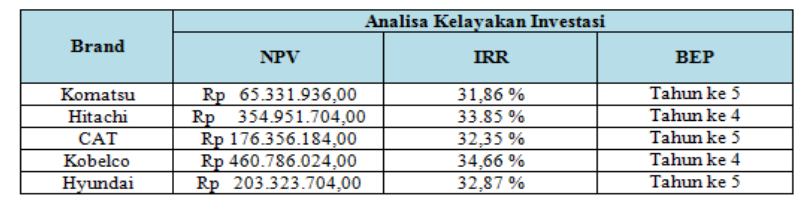

\section{Aspek Teknis}

Menghitung biaya operasional alat yang terdiri dari biaya bahan bakar, pelumas, workshop, perbaikan dan upah operator, sehingga diperoleh sebagai berikut

\begin{tabular}{|c|c|}
\hline brand & Biaya Operasional Excavator Kelas High Mode \\
\hline komatsu & $\operatorname{Rp} 909.508 .560,00 /$ thn \\
\hline hitachi & $\operatorname{Rp} 861.997 .600,00 /$ thn \\
\hline CAT & $\operatorname{Rp~} 1.024 .186 .832,00 /$ thn \\
\hline Kobelco & $\operatorname{Rp} 884.092 .756,00 /$ thn \\
\hline hyundai & $\operatorname{Rp} 869.613 .000,00 /$ thn \\
\hline
\end{tabular}

Kemudian menghitung produktifitas excavator kelas high mode, sebagai berikut :

\begin{tabular}{|c|c|c|c|}
\hline Brand & tipe & produktifitas & satuan \\
\hline komatsu & PC 300F-8Mo & 224,10 & $\mathrm{~m} 3 / \mathrm{jam}$ \\
\hline hitachi & $\mathrm{Z} \times 350 \mathrm{H}-5 \mathrm{G}$ & 249,00 & $\mathrm{~m} 3 / \mathrm{jam}$ \\
\hline CAT & $336 \mathrm{D} 2$ & 202,43 & $\mathrm{~m} 3 / \mathrm{jam}$ \\
\hline kobelco & SK 330 & 193,16 & $\mathrm{~m} 3 / \mathrm{jam}$ \\
\hline hyundai & R 330-LC9S & 208,31 & $\mathrm{~m} 3 / \mathrm{jam}$ \\
\hline
\end{tabular}

\section{Analisa Pengambilan Keputusan}

Berdasarkan ketiga indikator tersebut, maka excavator pada kelas high mode, Kobelco SK 330 penulis rekomendasikan untuk dipilih dalam aktifitas investasi, karena secara ekonomis Kobelco SK 330 memiliki nilai NPV tertinggi, persentase pengembalian modal atau IRR terbesar dengan waktu pengembalian tercepat.

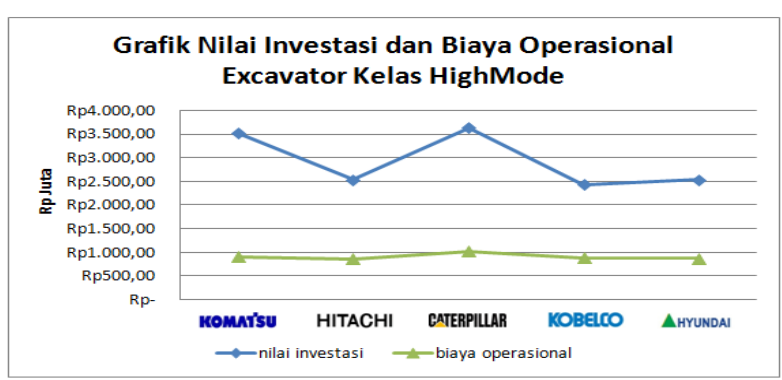

Bisa dilihat bahwa, nilai investasi excavator kelas high mode memiliki perbedaan yang sangat signifikan, dengan Caterpillar 33,05\% lebih tinggi daripada Hyundai atau selisih Rp.1.200.000.000,-Begitu juga dengan biaya operasional yang memiliki perbedaan cukup besar, dimana Caterpillar 336D2 membutuhkan biaya $15,09 \%$ lebih besar daripada Hyundai R330-LC9S atau selisih Rp. 154.573.832,-.

Secara ekonomis Kobelco SK330 layak untuk diinvestasikan, namun pada aspek teknis, Kobelco SK330 membutuhkan biaya operasional Rp. 884.092.756,-/tahun, ketiga tertinggi setelah Caterpillar 336D2 dan Komatsu PC 330F-8Mo. Selain itu, Kobelco SK330 justru memiliki nilai produktifitas terendah yaitu 193,16 m3/jam. Maka secara teknis, Kobelco SK330 


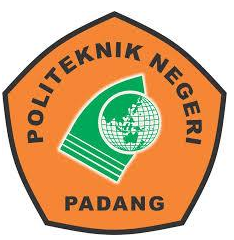

Available online at : http://ejournal2.pnp.ac.id/index.php/iirs/ Terakreditasi SINTA Peringkat 5 tidak direkomendasikan untuk digunakan sendiri, tetapi lebih cocok pada aktifitas investasi yang ditujukan untuk disewakan.

\section{KESIMPILAN \& SARAN}

1. Dalam menyusun indikator pemilihan excavator, aspek yang ditinjau adalah aspek ekonomis yang mencakup perhitungan biaya kepemilikan dan perbaikan alat. Kemudian penilaian kelayakan investasi dari masingmasing alat ini dilakukan dengan menggunakan metoda NPV, IRR dan BEP. Aspek kedua adalah aspek teknis yang mencakup perhitungan biaya operasional dan produktifitas masing-masing alat.

2. Dari ketiga kelas yang penulis komparisi, terlihat bahwa persaingan terketat untuk memikat pasar terjadi pada excavator kelas medium. Ini dapat dilihat dari selisih harga unit yang tidak signifikan dan nilai NPV yang hampir merata serta pengembalian modal yang hampir sama dengan waktu BEP seluruh brand terjadi pada tahun ke-4 kepemilikan.

3. Untuk pemilik alat, penulis tidak merekomendasikan untuk melakukan penjualan unit ketika umur ekonomis alat telah habis 5 tahun, karena terdapat beberapa unit yang BEP-nya baru terjadi pada tahun ke-5 kepemilikan. Penulis merekomendasikan untuk melakukan peremajaan alat ketika umur alat sudah 5 tahun.

4. Pengambilan keputusan pada penelititan ini hanya bersifat rekomendasi dari hasil analisa penulis dan tidak bersifat mutlak, karena bisa jadi terdapat brand lain yang lebih cocok dengan kebutuhan calon investor dan faktor fanatisme investor terhadap suatu brand.

\subsection{Saran}

1. Untuk menghitung biaya operasional diharapkan untuk menghitung dengan rumus aktual dilapangan, sehingga hasil perhitungan sangat relevan dengan kondisi sebenarnya dilapangan.

2. Pada penelitian selanjutnya diharapkan untuk juga menganalisa biaya kepemilikan yang dihitung dengan menggunaka suku bunga atau pembelian secara kredit beserta dengan penyusunan diagram cash flow-nya. Sehingga mampu memberikan pertimbangan tidak hanya pembelian yang dilakukan secara cash, tetapi juga mampu memberikan pertimbangan dengan pembelian secara kredit.

3. Pada penelitian selanjutnya juga diharapkan untuk menggunakan metoda analisa kelayakan investasi yang lebih banyak untuk lebih memperkuat dalam pengambilan keputusan pemilihan alat.

4. Untuk penelitian selanjutnya diharapkan untuk bisa membuat hasil analisa yang disusun dalam satu tampilan tabulasi atau grafis, sehingga memudahkan pembaca atau investor untuk menentukan pelihan yang paling cocok dengan pilihan investor. 


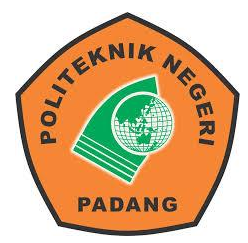

Available online at : http://ejournal2.pnp.ac.id/index.php/iirs/ Terakreditasi SINTA Peringkat 5

\section{DAFTAR PUSTAKA}

Robert J.Kodotaie, 1995, Analisis Ekonomi Teknik, Yogyakarta: PT. Andipratita Trikarsa Mulia.

Blank and Tarquin. (2012). Engineering Economy : International Edition. McGraw-Hill Companies, New York, America.

Blank and Tarquin. (2012). Engineering Economy : International Edition. McGraw-Hill Companies, New York, America.

Yacob Ibrahim, 2003, Studi Kelayakan Bisnis, Jakarta: PT. Asdi Mahasatya, hlm 1.

Fahrizal, dkk, 2013, Suistanable Forest Management Analysis on Conventiona Silviculture and Intensive Silviculture System: A Case Study at PT. Suka Jaya Makmur, West Kalimantan, Bogor: Institut Pertanian Bogor

Ferianto. 2007. Ekonomi Teknik : Analisa Pengambilan Keputusan. Yogyakarta : Penerbit ANDI.

Giatman M. 2005. Ekonomi Teknik. Jakarta : PT Raja Grafindo Persada.

Alfa Firdaus, Andi Hariyanto (2012). Analisa Keputusan Investasi Alat Berat di pertambangan Batu Bara PT IR. Jakarta : Universitas Mercu Buana

Rumengan. Michael Raynold, 2017, Skripsi : "Analisa Investasi Alat Berat Stone Crusher di Kota Bitung". Universitas Sam Ratulangi. Jurusan Teknik Sipil. Manado

Hariyanto. Andi, 2012, Skripsi : "Analisa Keputusan Pemilihan Alat Berat di Pertambangan Batu Bara PT.IR". Universitas Mercu Buana. Jurusan Teknik Industri. Jakarta

Yuwono. Tommy Cristhian, 2015, Skripsi : “ Analisis Ekonomis Sebagai Dasar Pengambilan Keputusan Dalam Penggantian Excavator."Jurusan Teknik Sipil, Universitas Krisren Petra, Jakarta
Clive Gray, dkk. 2007. Pengantar Evaluasi Proyek. PT. Gramedia Pustaka Utama. Jakarta.

https://books.google.co.id/books?isbn=9 795112295

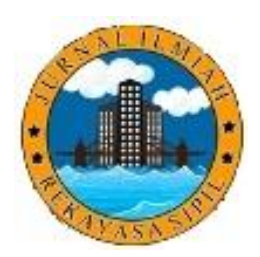

